\title{
«Poppy Field» by Ermolai Lopakhin and «Poppy Fields» by European Impressionists (based on the Play of A. P. Chekhov «The Cherry Orchard»)
}

\author{
Nikolaeva Svetlana Yurievna ${ }^{1}$ \\ Professor of Tver State University, \\ Tver, Russia. \\ (date of receiving: December, 2019; date of acceptance: March, 2020)
}

\begin{abstract}
In the play AP Chekhov's "The Cherry Orchard" is implemented receiving of ekphrasis: the text is full of associative links, symbols, culture name formed the aesthetic code of Russian and European impressionism. Chekhov recreates the cultural context in which the Russian intelligentsia lived at the turn of XIX-XX centuries. Many fragments of the "Cherry orchard" find their Parallels in the paintings of European impressionist artists. In particular, the story Lopakhin about the field of poppies is clearly reminiscent of a series of paintings by Claude Monet "Poppy Field in Giverny". Chekhov's ekphrasis is clearly also drawn to the paintings of Van Gogh (still life with poppies and landscapes with poppy fields).

Many microcircuits and details of the "Cherry Orchard" can be compared with the works of Levitan, Van Gogh, Seurat and others. Chekhov's author's position is as follows: his heroes are under the charm of European culture, their mentality has changed, they lose their national identity, become "Westerners", want to leave Russia. They are "Russian Europeans", they are inherent in "lackey thought" (Dostoyevsky's expression). The genre of Comedy and farce becomes a form of expression of author's condemnation of the Russian intelligentsia.
\end{abstract}

Keywords: Impressionism, Ekphrasis, Chekhov, Cherry Orchard, Claude Monet, Van Gogh, National Identity.

1. E-mail: synikolaeva@rambler.ru 


\title{
«Маковое поле» Ермолая Лопахина и «маковые поля» европейских импрессионистов (по пьесе А.П. Чехова «Вишневый сад»)
}

\author{
Николаева Светлана Юрьевна ${ }^{1}$ \\ Профессор, Тверский государственный университет, \\ Тверь, Россия. \\ (дата получения: декабрь 2019 г.; дата принятия: март 2020 г.)
}

\begin{abstract}
Аннотация
В пьесе А.П. Чехова «Вишневый сад» реализован прием экфрасиса: текст насыщен ассоциативными связями, символами, культуремами, сформированными эстетическим кодом русского и европейского импрессионизма. Чехов воссоздает культурный контекст, в котором жила русская интеллигенция рубежа XIX-XX веков. Многие фрагменты «Вишневого сада» находят свои параллели в полотнах европейских художников-импрессионистов. В частности, рассказ Лопахина о маковом поле явно напоминает серию картин Клода Моне «Маковое поле в Живерни». Чеховский экфрасис явно обращен также к картинам Ван Гога (натюрморты с маками и пейзажи с маковыми полями).

Многие микросюжеты и детали «Вишневого сада» можно сопоставить с работами Левитана, Ван Гога, Сёра и других. Авторская позиция Чехова такова: его герои находятся под обаянием европейской культуры, их ментальность изменилась, они утрачивают национальную идентичность, становятся «западниками», хотят уехать из России. Они «русские европейцы», им присуще «лакейство мысли» (выражения Достоевского). Жанр комедии и фарса становится формой выражения авторского осуждения российской интеллигенции.
\end{abstract}

Ключевые слова: Импрессионизм, Экфрасис, Чехов, «Вишневый Сад», Клод Моне, Ван Гог, Национальная Идентичность.

1. E-mail: synikolaeva@rambler.ru 


\section{Введение}

Пьеса А.П. Чехова «Вишневый сад», казалось бы, изученная вдоль и поперек, не перестает удивлять своими поэтическими тайнами и эстетическими изысками, заставляет новые поколения исследователей вновь и вновь обращаться к проблемам, решение которых порой представляется хрестоматийно ясным. Например, до сих пор определение «лирическая комедия», данное Горьким и прижившееся в чеховедении, вызывает сомнения, не снимает разногласий в трактовке жанровой природы произведения. Комедия, местами даже фарс, как уверял сам Чехов? Мелодрама, как поняли Станиславский и Немирович-Данченко? Или все-таки лирическая комедия, как предлагал М. Горький? Многочисленные свидетельства и аргументы драматурга, в частности его слова из письма к жене от 18 декабря 1901 года: «Я все мечтаю написать смешную пьесу, где бы черт ходил коромыслом» и многие другие высказывания часто не принимаются во внимание. Многим исследователям и критикам хочется поправить Чехова. Так, по мнению очень тонкого ценителя чеховского творчества Ю. Соболева, новаторство «Вишневого сада» заключается «в своеобразном сочетании гротескнокомического с лирико-драматическим. Но это сочетание не всегда кажется органическим, естественно вытекающим из существа пьесы. «Вишневый сад» не избавлен от двупланности, от несглаженных противоречий» (Соболев 1934. 234).

Разночтения и разница мнений возникают потому, что гротескнокомическое и лирико-драматическое в процессе чтения ошибочно разделяют: вот эпизод со слезами, а вот сцена фарсовая. На самом деле у Чехова каждый эпизод внутренне очень органичен, имеет синтетический (амбивалентный) характер, пронизан романтической иронией, которая вовсе не предусматривает «сглаживания противоречий», а одновременно демонстрирует разные, подчас противоположные аспекты того или иного образа. Обращение к возможностям 
романтической иронии - один из основных путей формирования комедийной природы пьесы А.П. Чехова. Романтическая ирония как эстетический принцип позволяет художнику обнаруживать сосуществование и взаимодействие высокого и низкого в окружающей действительности, создавать такие художественные феномены, в которых синтезируются комическое и трагическое.

\section{Основная часть}

Особенно ярко это видно на многочисленных примерах чеховского экфрасиса. В драматургическом произведении автор лишен возможности выражать прямо свою точку зрения - почти лишен, так как на сцене говорят герои, но не их создатель. Спасают положение и дают дополнительные возможности авторские ремарки и те фрагменты реплик персонажей, в которых так или иначе реализован прием экфрасиса, то есть описания описания картины природы, живописной картины, музыкального произведения и т.п. У Чехова в «Вишневом саде» и в авторских ремарках, и в монологах героев довольно много очень значимых, на наш взгляд, описательных фрагментов, насыщенных ассоциативными связями, символическими значениями, намеками, культуремами и мифологемами.

Вполне в духе времени Чехов воссоздает тот культурный контекст, в котором жила русская интеллигенция рубежа XIX-XX веков. Если говорить об искусстве, то это, прежде всего, чрезвычайно модные течения импрессионизм и постимпрессионизм, о приверженности к которым Чехова писали многие критики, в том числе Д.С. Мережковский, Н.К. Михайловский, А.С. Глинка (Волжский) и другие. Чехова называли «бессознательным импрессионистом», «натуралистом-импрессионистом», «символистом-импрессионистом» и тем самым «переносили его истоки на европейскую почву» (Громов 1989. 136). Некоторые коррективы в концепции старой критики внесли позднейшие 
исследователи, указав, что «импрессионистская поэтика способствовала углублению чеховского реализма» (Кулиева 1988. 183).

Известно, что Чехов интересовался этим направлением и был хорошо осведомлен в данной области, был дружен с Левитаном, которого ставил выше иностранных живописцев, обсуждал с ним эти проблемы, вместе с А.С. Сувориным бывал на выставках импрессионистов в Париже (1891 и др.) (Громов 1989. 269), не мог не быть на крупнейшей французской художественно-промышленной выставке в Москве 1891 г. и масштабной выставке французского современного искусства 1896 г. (Москва и Петербург), где были представлены полотна К. Моне и Ренуара. В России интерес к этому направлению был велик. Еще в 1876 г. журнал «Вестник Европы» опубликовал обзорную статью Э. Золя о второй выставке импрессионистов в Париже и творчестве ведущих художников этого направления. В 1890-е гг. в России о нем знали широко, о нем спорили ценители искусства, о нем говорили применительно к литературе (Д. Мережковский, Л. Толстой и др.). В 1900 году в Париже состоялась Всемирная выставка, которая вызвала активный отклик в России.

Многие фрагменты «Вишневого сада», микросюжеты высказываний, т.е. реплик и монологов героев, а также авторских ремарок находят свои параллели в полотнах европейских художников-импрессионистов или их последователей (постимпрессионистов и символистов). Случайно ли комнаты Раневской именуются «белая» и «фиолетовая»? Может быть, причиной тому не столько «французские корни характера» (Полоцкая 2004. 344) этой героини, a ее вкус, сложившийся под влиянием французских импрессионистов?

В частности, рассказ Лопахина о маковом поле («Я весной посеял маку тысячу десятин и теперь заработал сорок тысяч чистого. А когда мой мак цвел, что это была за картина! Так вот я, говорю, заработал сорок тысяч») явно содержит свернутый экфрасис и отсылает к популярной у импрессионистов 
теме маковых полей. Чехов вводит аллюзию прежде всего на серию картин Клода Моне, представленную такими полотнами (и их многочисленными вариантами), как «Маковое поле в Живерни» (1890), «Стог сена в Живерни» (1886), «Поле маков у Аржантея» (1973). Все эти пейзажи передают впечатление ветреной быстро меняющейся от солнечной к пасмурной погоды; стог сена, помещенный на переднем плане, помогает выделить средний план склоненные ветром к земле цветущие заросли маков; красные маки сочетаются с излюбленной у Моне топикой - тополями, похожими на человеческие фигуры, и стогами сена; на самой известной картине маковое поле служит обрамлением для изображения дворянской усадьбы и стаффажныхфигур женщины с ребенком, причем эти фигуры даны дважды, на заднем и переднем планах, чтобы дать зрителю ощущение динамики. Возникает ассоциативная связь с чеховской пьесой, где о маленьком сыне Любови Андреевны Раневской, утонувшем в семилетнем возрасте, также говорится несколько раз, чтобы вызвать у зрителя и читателя впечатление движения времени.

Чехов создает амбивалентный образ героя: Лопахин, как и многие «нетипичные» русские капиталисты (тот же П. Третьяков), любит искусство и ценит красоту («А когда мой мак цвел, что это была за картина!»), слово «картина» в его речи присутствует неслучайно, но вместе с тем он коммерсант, думающий о прибыли. И Чехов поддерживает эту ассоциативную связь упоминанием о прибыли в 40 тысяч: Лопахин, восхищаясь красотой («то-то была картина!»), не забывает упомянуть, что эта красота позволила ему заработать сорок тысяч чистого дохода. Известно, что импрессионисты, поначалу отвергаемые эстетами и подвергнутые обструкции беспощадной критикой, очень скоро стали цениться весьма высоко, их картины скупали американские коллекционеры, художники, тот же Моне, стали получать высокие гонорары, о чем широко писалось в отчетах о выставках импрессионистов, и в начале 1890-х гг. Моне уже зарабатывал по 100 тысяч франков в год (Ревалд 1962. 331). 
Добавим, что тему маков широко использовал и такой художник, уже из поколения постимпрессионистов, как Ван Гог. Он известен не только своими «Подсолнухами», но и рядом других запоминающихся образов, в том числе маками в натюрмортах и пейзажах. Маки присутствуют на таких его полотнах 1880-1890-х гг., как «Ваза с васильками и маками», «Ваза с красными маками», «Красные маки и ромашки», «Маки и бабочки», «Поле с маками», «Край пшеничного поля с маками», «Зеленые пшеничные колосья», «Пшеничные поля близ Овера», «Пейзаж в Овере» и др. Но если у Моне изображение маковых полей передавало трепет живой жизни, то у Ван Гога маки создают впечатление тревоги, драматизма, изломанности судьбы. И этот смысловой нюанс тоже находит соответствие в структуре образа Лопахина: этот герой не прямолинейный, не схематичный, а рефлексирующий, остро чувствующий, страдающий.

Надо сказать, что многие сюжеты Ван Гога, начинавшего свой путь в русле реалистической живописи и лишь на более зрелом этапе обратившегося к приемам авангардного искусства, типологически близки микросюжетам чеховской пьесы. Например, вспомним известный эпизод с потерянными Петей Трофимовым калошами: «В а р я. Петя, вот они, ваши калоши, возле чемодана. (Со слезами.) И какие они у вас грязные, старые...» Слезы Вари обусловлены ее собственными переживаниями, но на метатекстовом уровне могут быть отнесены, конечно, и к Петиной судьбе - этот «вечный студент» и «бесприютный скиталец» долго будет бродить по дорогам русской жизни в разбитых башмаках. Грязные, старые калоши Пети можно воспринимать как свернутый экфрасис, основанный на известной серии из 6 картин Ван Гога, посвященных башмакам (1887). Свернутый экфрасис у Чехова рассчитан на читательское восприятие, на работу читательского воображения, добавляющего недостающие элементы и воссоздающего целостную картину. 
Знаменитая картина Ван Гога «Едоки картофеля» (1885), а также «Голова крестьянки» и другие, изображающие простых людей, вызывают в памяти подробности жизни прислуги в доме Раневской. Обстановку бедности, скудости, подавленного настроения, душевных страданий и бесконечного терпения может воспроизвести в своем воображении читатель чеховской пьесы, особенно знакомый с картинами Ван Гога.

У голландского художника существовало собственное понимание пейзажа, близкое чеховскому: выражение субъективного, внутреннего восприятия природы через аналогию с человеком. Кредо художника выражено в словах: «Когда рисуешь дерево, трактуй его как фигуру» (Ван Гог, Винсент 2018). Этот принцип получил воплощение в таких картинах художника, как «Персиковое дерево в цвету» (1888), «Весна. Арль» (1888), «Оливковая роща с белым облаком» (1889), «Сельская дорога с кипарисами» (1890) и др. Не учитывая этот принцип, невозможно до конца понять такой эпизод:

Л ю б о в ь А н д р е е в н а. Посмотрите, покойная мама идет по саду... в белом платье! <..> Это она. <..> Направо, на повороте к беседке, белое деревцо склонилось, похоже на женщину.. <..> Какой изумительный сад! Белые массы цветов, голубое небо...

Этот экфрасис основан не только на сюжетах, близких к сюжетам Ван Гога, но и, судя по цветовой гамме, апеллирует к картинам Левитана («Цветущие яблони», 1896).

Думается, пейзаж и экфрасис Чехова гораздо ближе к картинам Ван Гога, нежели К. Моне (Тамарли 2014. 39-54). Прежде всего стоит обратить внимание на многочисленные картины Ван Гога, изображающие поля. Как правило, на переднем плане показан крестьянский труд, фигуры крестьян, повозки, орудия труда, колосья, средний план представлен как перемежающиеся фрагменты по-разному ритмизованного пространства, что создает эффект простора, дали, а на заднем плане показывается город, дымящие трубы заводов и фабрик, 
железная дорога, поезд. Подобная композиция присутствует на таких полотнах, как «Вид Арля. Жатва» (1888), «Жатва. Долина ла Кро. Арль» (1888), «Дорога в Овере после дождя» (1890), «Поля в Овере» (1890). Остро переживаемое столкновение двух цивилизаций, двух культур индустриальной, урбанистической и деревенской, патриархальной - вот смысл и значение картин Ван Гога.

Но и у Чехова подобный пейзаж есть во многих произведениях - например, в повести «Степь» (1888) мальчик Егорушка, подъезжая к большому городу, видит картину: «Обоз стоял на большом мосту, тянувшемся через широкую реку. Внизу над рекой темнел дым, а сквозь него виден был пароход, тащивший на буксире баржу. Впереди за рекой пестрела громадная гора, усеянная домами и церквами; у подножия горы около товарных вагонов бегал локомотив». Второе действие «Вишневого сада» начинается развернутой авторской ремаркой: «Поле. Старая, покривившаяся, давно заброшенная часовня, возле нее колодец, большие камни, когда-то бывшие, по-видимому, могильными плитами, и старая скамья. Видна дорога в усадьбу Гаева. В стороне, возвышаясь, темнеют тополи: там начинается вишневый сад. Вдали ряд телеграфных столбов, и далеко-далеко на горизонте неясно обозначается большой город, который бывает виден только в очень хорошую, ясную погоду. Скоро сядет солнце».

Известно, что в ходе работы над спектаклем Чехов требовал, чтобы декорации передавали необычайную для сцены даль и на горизонте был виден маленький паровозик. По большому счету, этот экфрасис тоже служит выражению главной авторской мысли о драматизме столкновения нового и старого, промышленно-железного и патриархально-деревенского. Стоит отметить, что железная дорога как символ нового века изображалась в живописи довольно часто (Ср.: Камиль Писсарро. «Железная дорога в Дьеппе» (1886); Исаак Левитан. «Полотно железной дороги» (1898-1899); «Полустанок» (1880-е)). 
Отметим значимое отличие пейзажей Ван Гога (который, кстати, начинал свою карьеру проповедником) от чеховских и левитановских. В чеховском экфрасисе присутствует часовня, хотя и заброшенная. У Левитана пейзаж часто одухотворен с помощью образа церковки, колокольни и т.п. (См. «У церковной стены. Этюд», 1885; «Тихая обитель», 1890; «Вечерний звон», 1892; «Над вечным покоем», 1894).

Чтобы завершить сопоставления с Ван Гогом, назовем еще картину «Ночное кафе. Арль» (1888), которая затрагивает тему бильярда. Многочисленные бильярдные термины Гаева, кий, сломанный Епиходовым, сам бильярд, который находится в соседней комнате, и зритель у Чехова, как и у Ван Гога, не видит игру на бильярде, только слышит голоса игроков. Эту серию чеховских деталей и подробностей в ее совокупности можно рассматривать как дискретный экфрасис (или даже диегезис), соотнесенный с артефактом - картиной Ван Гога.

Другая ветвь импрессионизма (даже постимпрессионизма, близкого к символизму) представлена творчеством художника Одилона Редона. Самые известные его картины - «Болотный цветок» (1885), «Летающее чудовище» (1890), «Глаз как шар» (рис. углем), «Крылатая голова над водами» (рис. углем). Редон посвятил свои творческие эксперименты изображению таинственного, мистического, и прижизненная критика оценивала его весьма резко: «Редон показывает нам, например, глаз, плывущий на конце стебля в бесформенном пейзаже. И вот собираются комментаторы. Одни уверяют нас, что глаз этот изображает око Совести; другие объявляют, что это око Неопределенности; третьи объясняют, что глаз этот синтезирует солнце, заходящее за гиперборейскими морями; четвертые, - что он символизирует мировую скорбь, причудливую водяную лилию, распустившуюся на черных водах невидимого Ахерона. Наконец, является самый мудрый толкователь и заключает: этот глаз на конце стебля - просто булавка для галстука. <..> 
Однако сегодня мы требуем, чтобы любая изображаемая вещь была точной; мы хотим, чтобы образы, порожденные мыслью художника, двигались, мыслили и жили» (Ревалд 1962. 112). Сам художник утверждал: «Я просто приоткрыл дверцу в тайну. Я создал вымысел. Их дело пойти дальше»; Редон «давал умам зрителей возможность развивать образы, которые он предлагал их воображению» (Там же. 113). Такая поэтика (опора на читательское воображение и восприятие), конечно, близка чеховской манере и принципам.

Глаз, который смотрит на весь окружающий мир, с высоты птичьего полета, изображенный Редоном, действительно похож на булавку для галстука, а также на воздушный шар, всплывающий над деревьями, полями, морями, горами и позволяющий человеку обозреть величественную картину природы. Этот глаз сам является частицей природы и вместе с тем он выше, прозорливее. Действительно, его можно соотнести с Недреманным оком, Оком совести. И с этим артефактом соотносится чеховский свернутый экфрасис - в монологе Пети Трофимова: «Неужели с каждой вишни в саду, с каждого листка, с каждого ствола не глядят на вас человеческие существа, неужели вы не слышите голосов». Монолог Пети Трофимова о душах умерших крепостных, которые глядят с каждого цветка, с каждой ветки в саду, соответствует картине Редона «Глаз как шар».

Импрессионисты рисовали не только пейзаж, но и жанровые сцены, что особенно важно в контексте выявления импрессионистического экфрасиса в «Вишневом саде» как произведении комедийного жанра. Художнику Сёра принадлежат такие нашумевшие картины, как «Воскресная прогулка на острове Гранд-Жатт» (1884-1886), «Парад» (1887-1888), «Канкан» (1889-1890), «Цирк» (1890-1891). Сёра эпатировал публику не только своей манерой пуантилизма (за что был обвинен в «пуантилистских сатурналиях»), но и, прежде всего, тематикой, отбором сюжетов, которые казались непристойными. Критика неистовствовала: 
«Канкан»- это «не что иное, как неистовый спазм задыхающегося карлика или вурдалака в периоде течки! < ..> Танцовщицы его ... так пикантны, что у меня захватывает дыхание, и, я уверен, не один человек стоит перед ними, разинув рот и стиснув руки, загипнотизированный лихорадочными восторгами чудовищной, унизительной непристойности. <..> наибольший интерес вызывает Сёра, один из потерявших разум мастеров, который оказал сильнейшее влияние на «Группу двадцати». «Канкан» в еще большей степени, чем «Гранд-Жатт», вызвавшая в свое время всеобщий смех, дает точное представление, в какое заблуждение можно впасть, опираясь на заумную доктрину этого художника, заключающуюся в отрицании всего, что существует, и в придумывании взамен некой новой формулы. Сёра, этот создатель искусства живописать пятнами сургуча, этот открыватель давно открытого, отмеченный печатью гения, малюет и мажет с великолепной невозмутимостью пациента сумасшедшего дома» (Там же. 296).

Отметим, что пуантилизм как художественный прием подвергался осмеянию как таковой, и во французской прессе появлялись анекдоты и юморески вполне в чеховском духе, в которых говорилось, что картины пуантилистов словно бы засижены мухами: «Муниципалитет распорядился закрыть выставку «Группы двадцати»: трое посетителей заболели оспой, которую подцепили перед картиной, выполненной точками; остальные охвачены ужасом. Некая светская молодая дама сошла с ума. Наконец, говорят, хотя факты не проверены, что жена одного провинциального мэра, имевшая неосторожность посетить выставку, находясь в интересном положении, разрешилась от бремени татуированным ребенком» (Там же. 297). Выскажем предположение, что Чехов тоже отдал дань критике пуантилизма в повести «Степь» (1888), где на постоялом дворе Мойсей Мойсеича висит гравюра с надписью «Равнодушие человеков»: «К чему человеки были равнодушны - понять было невозможно, так как гравюра сильно потускнела 
от времени и была щедро засижена мухами». Чеховская ирония в рамках живописного экфрасиса представляется глубоко продуманной, хотя и не обращена на какое-то конкретное полотно.

Зато сюжеты четырех вышеназванных картин Сёра вполне сопоставимы с экфрасисами «Вишневого сада». «Воскресная прогулка на острове ГрандЖатт» может служить иллюстрацией к следующей чеховской сцене: «Через сцену, опираясь на палочку, торопливо проходит Фирс, ездивший встречать Любовь Андреевну; он в старинной ливрее и в высокой шляпе; что-то говорит сам с собой, но нельзя разобрать ни одного слова. <..> Любовь Андреевна, Аня и Шарлотта Ивановна с собачкой на цепочке, одетые по-дорожному. Варя в пальто и платке, Гаев, Симеонов-Пищик, Лопахин, Дуняша с узлом и зонтиком, прислуга с вещами - все идут через комнату». Этакий парад-алле, в котором участвуют такие же персонажи и присутствуют такие же атрибуты (зонтик, собачка/обезьянка на цепочке, шляпы, саквояжи), что и на картине Cëpa.

Картина Сера «Парад» изображает оркестр, напоминающий еврейский оркестрик в пьесе Чехова. Фокусы и сальто-мортале гувернантки Шарлотты могут быть проиллюстрированы полотнами Сёра «Цирк» и «Канкан»: «В зале фигура в сером цилиндре и в клетчатых панталонах машет руками и прыгает». О Шарлотте Ивановне принято говорить, что эта «цирковая клоунесса сгущает лирическую тему Чехова и проясняет ее общечеловеческое содержание, она играет <..> ту же роль, что бродячие гимнасты и клоуны в творчестве Пикассо голубого и розового периода» (Зингерман 1988. 370). Но на самом деле литературный прообраз Шарлотты - это «одна из петербургских «камелий», описанных в цикле очерков И.И. Панаева «Петербургская жизнь», публиковавшихся в журнале «Современник» (1857) (Николаева 2002. 118). И, конечно же, не сгущенный лиризм Пикассо, а иронический потенциал картин Сёра наиболее точно передают сущность образа Шарлотты и чеховское отношение к ней, соотносится с жанром комедии. 
Любовь к России и к вишневому саду, к родному дому и тем более к «детской», к белой или фиолетовой комнате, к «шкафику», к «столику»- все это миф (Катаев 2005), иллюзия, мимолетное видение, мгновенное впечатление. Петя Трофимов уверяет: «Вся Россия - наш сад». Мы везде найдем себе пристанище. Сад не онтологическая категория для героев пьесы, а ценностная. Ценность ее даже можно измерить, исчислить в деньгах. Фирс упоминает, что когда-то сад давал большие урожаи, поэтому денег было не счесть! Для героев «Вишневого сада» нет абсолютных ценностей, у российской интеллигенции ценности преходящи и вполне заменяемы. Можно насадить другой сад, лучше прежнего. Вслед за Достоевским Чехов осуждает «русских европейцев», «лакеев мысли». Все они перелетные птицы, обобщенные в образе-символе Прохожего. Чехов маркирует своих героев «русских европейцев» с помощью деталей - культурем европейского импрессионизма.

Вероятно, назрела необходимость, обращаясь к «Вишневому саду», использовать понятие «русская идея», имевшее особую актуальность в русской литературе и философии на рубеже XIX-XX вв. и сохранившее эту актуальность теперь, уже на рубеже XX-XXI вв., вплоть до поэзии Ю.П. Кузнецова, «вписанной в культурное пространство всей русской литературы» (Редькин 2004.68) и других «почвенников», «указывающих духовный путь русскому народу» (Редькин 2010. 87). Российская интеллигенция, по наблюдениям Чехова, эту идею утратила.

\section{Заключение}

Итак, в пьесе «Вишневый сад» Чехов очень широко использует прием экфрасиса (по преимуществу свернутого, с учетом специфики драматургического произведения и его текстопостроения), в основном обращая его на европейскую культуру, на искусство импрессионизма и 
постимпрессионизма. Введение в текст пьесы данного образного пласта обусловлено авторской позицией, системой ценностей и онтологическими представлениями Чехова.

Импрессионистичность, сиюминутность, эфемерность, иллюзорность, текучесть ценностей и взглядов российской интеллигенции - вот предмет осуждения и осмеяния Чехова, вот основа комедийной жанровой сущности пьесы.

Для самого Чехова онтологическая сущность в этой комедии - Россия, показанная не риторически, а вполне реалистически, с помощью символического образа русской женщины - матери Яши, которая пришла повидаться, а потом проститься со своим «оевропеившимся» сыном, но так и не встретилась с ним.

\section{Литература}

1- Ван Гог, Винсент (2018). Ван Гог, Винсент. // https://ru.wikipedia.org/wiki. Дата обращения: 15.01.2018.

2- Громов М.П. (1989). Книга о Чехове. -М.: Изд-во «Современник». 384 с.

3- Зингерман Б.И. (1988). Театр Чехова и его мировое значение. -М.: Изд-во «Наука». $521 \mathrm{c}$.

4- Катаев В.Б. (2005). «Вишневый сад» как элемент национальной мифологии // Чеховиана. «Звук лопнувшей струны». К столетию пьесы «Вишневый сад». М.: Изд-во «Наука». С. 9-18.

5- Кулиева Р.Г. (1988). Реализм А.П. Чехова и проблема импрессионизма. Баку: Изд-во «Элм». $186 \mathrm{c}$.

6- Николаева С.Ю. (2002). Гувернантка или клоунесса? (Феномен чеховской Шарлотты) // Драма и театр. Сборник научных трудов. Тверь: Изд-во «Тверской государственный университет». С. 116-121.

7- Панаев И.И. (1857). Петербургская жизнь // Современник. 1857. № 3. С.143167.

8- Полоцкая Э.А. (2004). Франиузские корни характера Раневской // Полоцкая Э.А. «Вишневый сад». Жизнь во времени. -М.: Изд-во «Наука». С. 344-359.

9- Ревалд Дж. (1962). Постимпрессионизм. Л.: Изд-во «Искусство». 464 с. 
10- Редькин В. А. (2010). Роль «Слова о Законе и Благодати» Илариона в поэмецикле Ю.П. Кузнецова «Путь Христа» // Вестник Тверского государственного университета. Серия: Филология. 2010. № 21. Вып. 5. С. 81-87.

11- Редькин В.А. (2004). «Русская идея» Юрия Кузнецова // Вестник Тверского государственного университета. Серия: Филология. 2004. № 2 (4). Вып. 1. С. $48-68$.

12- Соболев Ю.В. (1934). Чехов. -М.: Изд-во «Журнально-газетное издательство». $336 \mathrm{c}$.

13- Тамарли Г.И. (2014). Чехов и Клод Моне: концепџия пейзажа // Тамарли Г.И. Синхронный диалог Чехова с культурой. Таганрог: Изд-во «Таганрогский государственный литературный и историко-архитектурный музейзаповедник». С. 39-54.

\section{Bibliography}

1- Van Gog, Vinsent (2018). Van Gog, Vinsent. // https://ru.wikipedia.org/wiki. Data obrashhenija: 15.01.2018.

2- Gromov M.P. (1989). Kniga o Chehove. -M.: Izd-vo «Sovremennik». 384 s.

3- Zingerman B.I. (1988). Teatr Chehova i ego mirovoe znachenie. -M.: Izd-vo «Nauka». $521 \mathrm{~s}$.

4- Kataev V.B. (2005). «Vishnevyj sad» kak jelement nacional'noj mifologii // Chehoviana. «Zvuk lopnuvshej struny». K stoletiju p'esy «Vishnevyj sad». -M.: Izd-vo «Nauka». S. 9-18.

5- Kulieva R.G. (1988). Realizm A.P. Chehova i problema impressionizma. Baku: Izdvo «Jelm». $186 \mathrm{~s}$.

6- Nikolaeva S.Ju. (2002). Guvernantka ili klounessa? (Fenomen chehovskoj Sharlotty) // Drama i teatr. Sbornik nauchnyh trudov. Tver': Izd-vo «Tverskoj gosudarstvennyj universitet». S. 116-121.

7- Panaev I.I. (1857). Peterburgskaja zhizn' // Sovremennik. 1857. № 3. S.143-167.

8- Polockaja Je.A. (2004). Francuzskie korni haraktera Ranevskoj // Polockaja Je.A. «Vishnevyj sad». Zhizn' vo vremeni. -M.: Izd-vo «Nauka». S. 344-359.

9- Revald Dzh. (1962). Postimpressionizm. L.: Izd-vo «Iskusstvo». 464 s.

10- Red'kin V. A. (2010). Rol' «Slova o Zakone i Blagodati» Ilariona v pojeme-cikle Ju.P. Kuznecova «Put' Hrista» // Vestnik Tverskogo gosudarstvennogo universiteta. Serija: Filologija. № 21. Vyp. 5. S. 81-87.

11- Red'kin V.A. (2004). "Russkaja ideja» Jurija Kuznecova // Vestnik Tverskogo gosudarstvennogo universiteta. Serija: Filologija. 2004. № 2 (4). Vyp. 1. S. 48-68. 
12- Sobolev Ju.V. (1934). Chehov. -M.:: Izd-vo «Zhurnal'no-gazetnoe izdatel'stvo». $336 \mathrm{~s}$.

13- Tamarli G.I. (2014). Chehov i Klod Mone: koncepcija pejzazha // Tamarli G.I. Sinhronnyj dialog Chehova s kul'turoj. Taganrog: Izd-vo «Taganrogskij gosudarstvennyj literaturnyj i istoriko-arhitekturnyj muzej-zapovednik». S. 39-54.

HOW TO CITE THIS ARTICLE

Николаева С. Ю. (2020). «Poppy Field» by Ermolai Lopakhin and «Poppy Fields» by European Impressionists (based on the Play of A. P. Chekhov «The Cherry Orchard»). Issledovatel'skiy Zhurnal Russkogo Yazyka i Literatury, 8(2), 51-68.

DOI: 10.29252 iarll.16.53

URL: http://journaliarll.ir/index.php/iarll/article/view/127

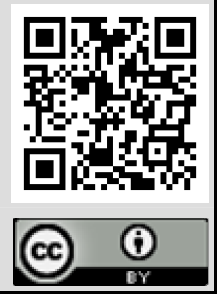




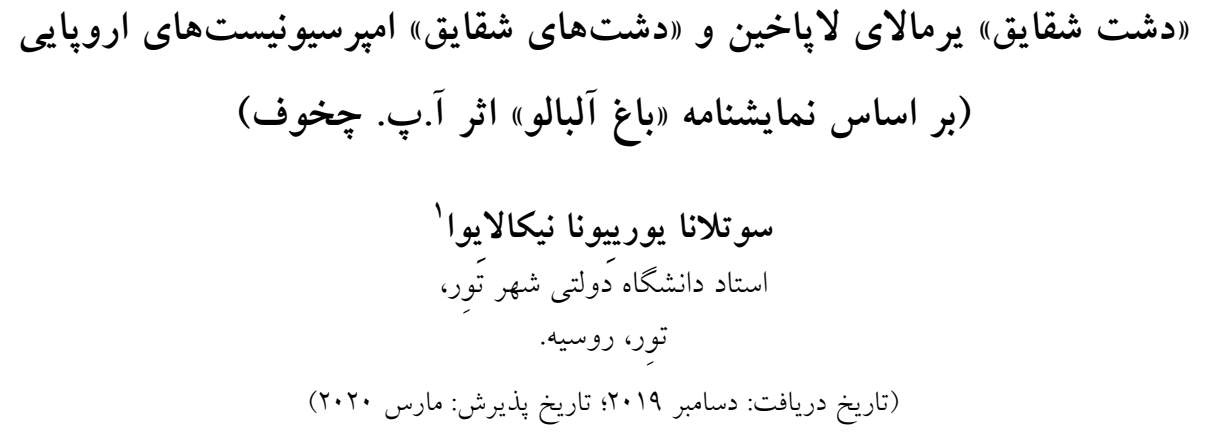

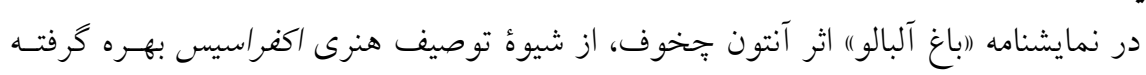

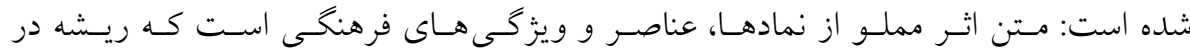

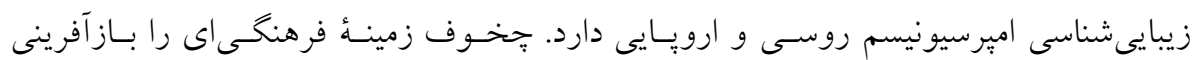

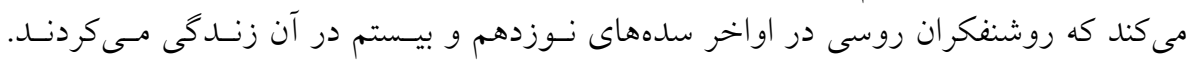

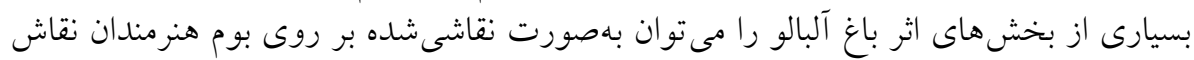

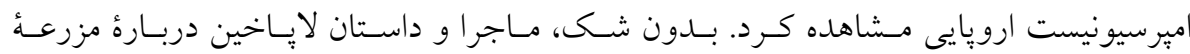

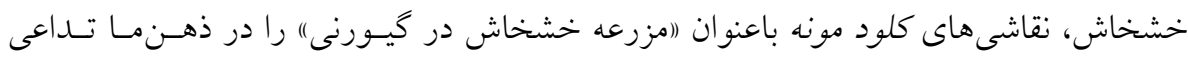

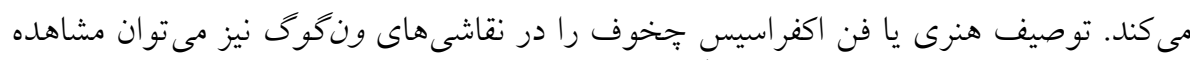

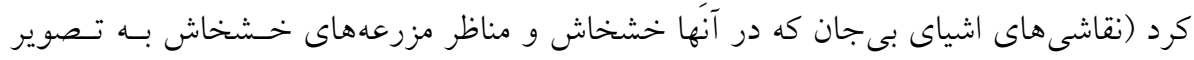

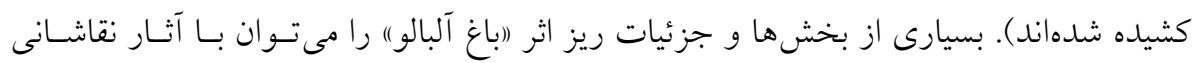

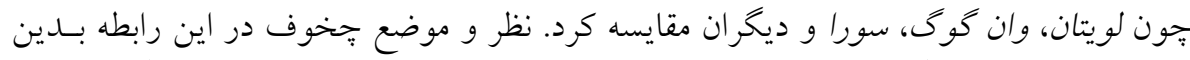

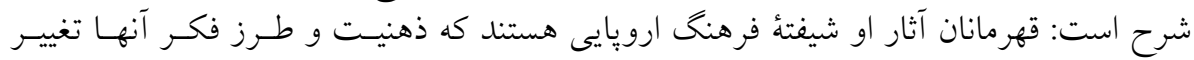

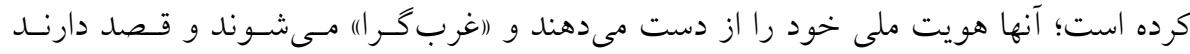

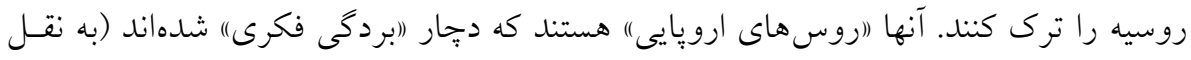

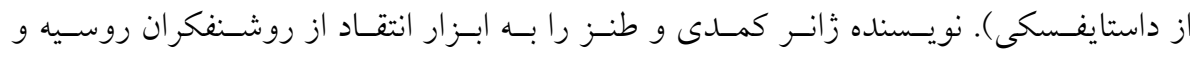

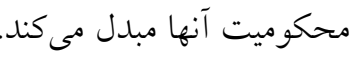

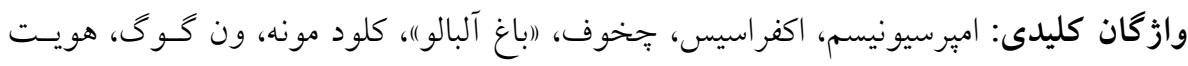

